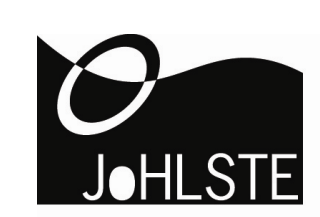

Journal of Hospitality, Leisure,

Sport \& Tourism Education

Vol. 6, No. 2.

ISSN: 1473-8376

www.heacademy.ac.uk/hlst/resources/johlste

PRACTICE PAPER

\title{
A Wolf in Sheep's Clothing? An Analysis of Student Engagement with Virtual Learning Environments
}

\author{
Crispin Dale (c.dale@wlv.ac.uk) and Andrew Lane (a.m.lane2@wlv.ac.uk) \\ School of Sport, Performing Arts and Leisure, University of Wolverhampton, Gorway Road, \\ Walsall, West Midlands WS12 4TB \\ DOI:10.3794/johlste.62.156 \\ ○Journal of Hospitality, Leisure, Sport and Tourism Education
}

\begin{abstract}
The growth in the use of virtual learning environments to support learning and teaching should be accompanied by research to examine their effectiveness. The aim of this study was twofold: a) To explore the views, opinions and experiences of student engagement or non-engagement in online learning activities; b) To use this knowledge to develop learning and teaching strategies that enhance student engagement with online learning activities.
\end{abstract}

Focus groups were conducted with students studying leisure and tourism degree programmes to explore reasons for usage and non-usage of the online activities in the Wolverhampton Online Learning Framework (WOLF). Results identified issues related to student awareness, motivation, behaviour and learning approaches, assessment and technical factors. Findings from the study have implications for practice, including how to enhance the relevance of information, technical factors, enhancing awareness and links with assessment.

Crispin Dale is a Principal Lecturer in Technology Supported Learning in the School of Sport, Performing Arts and Leisure at the University of Wolverhampton. His current research interests include the use of virtual learning environments and the use of podcasting to support student learning.

Andrew Lane is a Professor in Sport Psychology and Learning and Teaching in the School of Sport, Performing Arts and Leisure at the University of Wolverhampton. He is a chartered psychologist from the British Psychological Society and accredited by the British Association of Sport and Exercise Sciences. 
Keywords: Virtual learning environments; WOLF; Online activities; Internet; Student engagement; Online discussion

\section{Introduction}

The use of virtual learning environments (VLEs) has become a significant feature of higher education, with the majority of institutions now incorporating this technology into their wider learning and teaching strategies. It is useful to define what is understood by a VLE. The Joint Information Systems Committee (JISC) defined a VLE as "the components in which learners and tutors participate in online interactions of various kinds, including online learning" (cited in Weller et al., 2005: 253). Johnson (2005: 12) notes four factors driving change in higher education that are influencing the use of web-based learning and VLEs. These include:

a) economic changes with a reduction in budgets and financial resources;

b) societal trends and the increasing desire for convenient, mobile and flexible learning opportunities;

c) employability trends and the demand for flexible, multitasking employees who are computer literate; and

d) that computers are a 'stable asset' in society, impacting upon every aspect of our personal and professional lives.

Thus the model of learner engagement has changed significantly in recent years, with opportunities being created which offer more stimulating learner experiences. Indeed, although it is acknowledged that the traditional learning model will probably not disappear; opportunities will increase for more creative 'blended' learning approaches (Wise, 2005).

Engagement with the University of Wolverhampton's own VLE (WOLF - Wolverhampton Online Learning Environment) by both staff and students is a key strategic priority for the university. The aim established in 2002 was, by 2005, to develop the interactive learning environment whereby the 'majority of technology-based learning undertaken by learners will involve them in active participation in online activities in a media-rich environment' (University of Wolverhampton, 2002). However, current practice has demonstrated that, even though some students choose to engage with the interactive learning activities, the majority decide not to, and are content with downloading module lectures and notes without interacting with the online activities that have been developed to assist their learning. This receiving but not giving approach needs further exploration if the proposed effectiveness of the university's VLE, in terms of supporting and enhancing student learning, is to be achieved.

\section{Learner engagement with the VLE}

A VLE could serve as a useful platform for supporting and engaging learners in the educational experience, as a range of learning activities can be powered through a VLE. Some VLEs, such as WebCT, Learnwise and Blackboard, have been created commercially, whereas others have been developed in-house by HE institutions themselves. This is the case for the University of Wolverhampton's own VLE (WOLF), which has been in existence since 1999.

A number of interactive functions can be performed on WOLF. These include formative assessment questions, such as multiple choice and fill-in the blanks, and collaborative learning activities such as discussion forums (see Lane et al., 2006). Students can also upload materials themselves onto WOLF. This is a useful function when setting activities where students may be asked to prepare a summary sheet of their findings that can then be shared with other learners on the programme via WOLF. The use of the VLE in this way shifts control and responsibility to the learner, thus developing independence and autonomy in the learning experience (Chou and Liu, 2005). VLEs can encourage deep learning experiences by offering feedback that initiates the learner to read more widely around the subject matter. Indeed, students who fully engage with VLEs are found to encounter higher levels of deep learning and significantly higher levels of strategic learning when compared to 
those who use VLEs minimally (Gibbs, 1999). Chou and Liu (2005) also found that learning engagement was higher when using a VLE than when using traditional models of learning. VLEs allow for interaction and communication, and the ability of the learner to post/email thoughts and reflections instantaneously enables them to engage more with the learning material. Reflective skills can thus be developed, as there is a greater amount of time for the learner to interact with the learning material (for example, through online discussions) (Johnson, 2005). When compared with students who did not use VLEs, research has shown a greater sense of 'connectedness' among students, and between staff and students, who use VLEs, leading to higher completion rates (Enjelvin, 2005; Pavey and Garland, 2004; Thurston, 2005). However, previous research should be viewed with an element of caution. A limitation with proposing that VLEs are better than traditional methods is that the VLE is new and traditional is old. All participants know traditional, and the benefits of using VLEs could be explained by their novelty.

The extent to which learners engage with VLEs is dependent upon their design and functionality. Weller et al. (2005) identify two different approaches to the design of VLEs. One is the monolithic or integrated approach, where all the online learning tools are housed within one software package. The alternative is the component or hybrid architecture approach, where the system also incorporates the tools of free or open source software. WOLF can be associated with the former approach, possibly due to its development in-house solely for the purpose of supporting University of Wolverhampton students. In their research into the use of different types of VLE systems, Weller et al. (2005) found that students prefer a VLE that takes a component approach, although caution is emphasised, as students are not always experts on what should be in the curriculum. Stefanov et al. (1998) note that interactivity needs to be a crucial design feature of a VLE as it will motivate and engage the learner. They note that the 'implementation of interactivity can be perceived as an art because it requires a comprehensive range of skills, including an understanding of the learner, a deep understanding of software engineering, deeper knowledge about the contemporary instructional design principles and aesthetical design of the multi-media interface' (Stefanov et al., 1998:85). Furthermore, Boyle (2005) notes that many stakeholders need to be involved in the successful implementation of a VLE in the learning and teaching environment. Diversity of stakeholders, incorporating technologists, academics, students and administrators, can bring about conflict, which in turn can complicate the successful implementation of a VLE (Whitworth, 2005).

Engagement with WOLF has not necessarily reflected the positive outcomes of interactivity and connectedness among learners that other studies have found. Engagement has predominately been based around what Haven and Botterill (2003) refer to as a content plus support model, where the VLE acts as a deposit for lecture notes and other materials (Dale 2003). Hall (2001) describes the process through which lecturers are encouraged to initiate student usage of VLEs through downloading lecture material. However, use of VLEs as a deposit for class content such as lecture notes and overheads is a minimalist approach (Dale, 2003) and does not encourage the full potential of the VLE and its capabilities. As a result of previous leaning and teaching research projects by the research team, a number of modules have embraced interactive learning activities, including differentiated selfassessment questions (Lane et al., 2006) and discussion groups (Dale and Lane, 2004). Where 'interactive' learning tools have been employed as part of a tutor's wider learning and teaching strategy, the engagement of these by students has often been sporadic and inconsistent (Khutan, 2003; Lane et al., 2006). Research has thus noted that there needs to be more rigorous evaluation of engagement with VLEs (Dale and Lane, 2004).

\section{Methods}

Previous studies in this area have predominately taken a quantitative approach to the analysis of the engagement with online learning tools in WOLF (Roberts and Simkins, 2002; Protheroe and Hill, 2003; Lane et al., 2006). It is argued that qualitative research should also be used to gather the views, opinions and experiences of students that would otherwise be 
difficult to collect using quantitative approaches. A number of modules taught by the research team now have a permanent resource base of online learning activities that students can engage with on an ongoing basis. For the purposes of this study, these modules were used as the sample for three focus group interviews. The first focus group included eight Level 3 Leisure Management students; the second consisted of six MSc Sport and Exercise Science students; and the third of six Level 1 Hospitality, Tourism and Event and Venue Management students. Level 2 students were not involved, as the research team were not delivering modules at this level at the time of the study. The overall sample consisted of ten males and ten females. It was a deliberate strategy to target students from a wide range of levels, backgrounds and interests. An acknowledged limitation is that the relatively small sample size precludes generalising results to a wider population. The primary objective of the research was to explore themes that emerged consistently across student groups rather than to identify the idiosyncrasies of specific courses.

Students were asked to volunteer to participate in the research project, with the nature of their involvement in the study made clear from the outset. A standardised interview guide was read aloud to each focus group, outlining how the interview would proceed (Berg, 2001). The research team conducted the interviews, and participants were informed that they should be totally open in any views and opinions expressed. The main emphasis was that there were no right or wrong answers, only differing points of view. Participants were asked to listen respectfully to the views of others, even if they disagreed. Before starting the focus groups, participants were asked whether they understood the interview guidelines. All participants were asked to respect the confidentiality of others regarding information disclosed within the focus groups. All participants provided informed consent for this procedure. Participants were further informed that their comments would remain anonymous and the data analysis would make no reference to any personal information that may reveal their identity. A semi-structured interview schedule was used for both focus groups. The questions used to guide the interview included:

- What do you use WOLF for?

- Are you are aware of the activities? If so, which ones?

- To what extent do you feel you have learnt from using the activities?

- To what extent do you feel WOLF has helped you to succeed in your modules?

- What strategies would help you learn more from using the WOLF facilities?

An accepted limitation is that lecturing staff ran the focus groups, which arguably could lead to students providing guarded answers. However, it should be indicated that, once the initial question was asked, discussions between students flowed, suggesting that students were willing to converse openly with their lecturer. It is of course possible that different data would have emerged if a neutral lecturer - that is, one the students did not know - sought to collect data. Furthermore, it is suggested that members of the research team who collected the data were able to reflect critically on their data analysis skills and this forms a key aspect of their ongoing professional development.

The interviews were tape-recorded and subsequently transcribed. Data were analysed using thematic content analysis, drawing upon common themes generated from the focus group interviews.

\section{Results and discussion}

An aim of this study was to explore ways in which students could further engage in the interactive online learning tools and thus increase the effectiveness and overall quality of the learning environment. Analysis of focus group data yielded a number of themes including: reasons for WOLF usage; explanations for usage and non-usage of interactive materials; suggestions to improve WOLF; and thoughts about sharing work. 
When the results are viewed collectively, students reported that their main motivation for using WOLF was for downloading content, which was not unusual given the primary focus of the study and the authors' previous experience of students' use of VLEs:

Yeah, I just used it (WOLF), um, to print off the lecture notes just before I come to the lecture ...so the lecture is easy to follow.

This, in itself, is a complementary factor of using VLEs to support learning. Students can engage with the in-class session more fully having the assistance of lecture notes to follow rather than copying down slides word for word in the lecture session.

Students provided explanations for usage and non-usage of interactive materials. With particular reference to WOLF-based learning tools such as 'activities' and the 'discussion' group facilities, students reported that they: a) were not aware of them; or b) did not like them; or c) were used to getting the information somewhere else; or d) did not realise the value of the activities. From these perspectives, the research findings can be conceptualised into a further three themes: differences in learning styles; student motivation towards assessment; and the design and functionality of the VLE.

\section{Differences in learning styles}

Different experiences of using the VLE for interactive activities such as the multiple choice questions existed between first-year students and those in the final year of their studies. Level 1 students were much more receptive to engaging with the online activities:

They're [multiple choice questions] useful because you can go back to them at the end of the semester and refresh your memory.

Some of the questions got me thinking and I learn better that way, I absorb the information better.

Level 3 students can become strategic in what they need to do to achieve and can see additional activity as a pointless exercise. Previous research by Dale and McCarthy (2006) has noted the 'strategic' and instrumentalist learning styles of students approaching the latter stages of their studies. It would appear that the VLE is used as part of this overall strategic approach to learning. Indeed, the exploration of why students used WOLF highlighted issues such as time and awareness of the relationship between doing the activity and the skills needed to pass the assessment. A typical quote from a Level 3 student was:

But in terms of the online activities, I have not done them, because, well, I'm just prioritising my time. My priorities are to get the case studies done and maybe these activities will help, but I feel restricted on time anyway. All my spare time is devoted to research and my case study and getting that done.

I know that I'm in the third year now I've got so used to it. All I use WOLF for is to get the lecture notes and getting assessment guides. I do not actually look for things like that on the tools menu.

Given that an aim of the project was to explore usage of activities, further probes about the utility of these were used. Students reported that, although they were aware of these additional resources, usage of them was not ingrained in their typical style of learning, and they preferred to use more traditional approaches. One student reported:

Yeah, it probably would, but the way I saw it your research for your assignment does those sorts of things for you ...so rather than sit in front of the computer doing it, you get stuck into habits of looking in books and doing it. 
It depends on how confident you are in your own ability. When you see the questions on there, and think, I know them anyway. So there is no point doing them, and you might not use them because you are confident in your own ability that you know what you are doing.

Another theme running through the usage of WOLF, which would suggest a strategic approach to learning, was sharing work with others. As mentioned earlier, WOLF enables students to upload materials that they may have prepared for an in-class activity and this allows all students to access and view each other's materials. However, if this relates directly to work required for an assessment, students reported that giving other students ideas might detract from their own grades. One student suggested:

Possibly, although in the back of my mind I am thinking that I am giving other people answers here. It is a pretty bad way of looking at things but it is in the back of your mind, you think why shall I tell them anything.

This contribution of knowledge by the student also related directly to non-engagement with the discussion forums in WOLF. The desire for anonymity was another strong theme that emanated from usage and non-usage of the discussion forum facilities in particular. All students were reluctant to engage with online discussion activities. As mentioned previously, it could be argued that the strategic nature of Level 3 students led to their non-usage.

However, Level 1 students also expressed a reluctance to be seen to be engaging with the online discussions:

I'm going to look stupid if I'm the first person to put something on there... and then people would comment about you the one person who used the discussion group.

It's important for me that people are present; when it's online it's a bit impersonal.

Dale and Lane (2004) have argued previously that poor motivation, low self-confidence and students' anticipated feelings of embarrassment if their peers interpret their work as poor are some of the reasons for non-usage of discussion forums. They have put forward strategies to encourage greater engagement by students with online discussion forums. Hakkinen (2003) further notes that learners need to be supported in their collaborative learning activities.

\section{Student motivation towards assessment}

One key finding concerned student motivation being driven primarily by assessment, and to some extent this determined student use of the VLE for this purpose. Thus the comments related to student learning and assessment led to further probes regarding the extent to which WOLF-based activities should be assessment driven. Students reported:

More people would definitely do them, yeah, cos otherwise it just like work for you, and you are wasting your time putting them on there.

They [the other students] are not going to get it done without a little bit of pressure put under them. If you are going to give us pressure to get it done in a specific amount of time, you have got to do that.

Another internally funded research project conducted by the English Department at the University of Wolverhampton has noted the positive outcome of the use of 'assessed' discussion forums by degree students studying English (Miles et al., 2006). This further highlights the motivation that assessment brings to student learning and which can be driven via the VLE. However, it should be recognised that this success could be due to the differences in learning styles between traditional humanities-related subjects and students studying vocational subjects. 


\section{Design and functionality of the VLE}

As highlighted by Stefanov et al. (1998), the design of the VLE can determine the extent of interaction by students. Given the lack of usage and interaction with the online activities, students were asked to suggest ways to improve WOLF.

I think that sometimes people really don't know about these activities, maybe it would seem a good idea that the activities are with the lecture.

As mentioned earlier, WOLF is categorised as a monolithic system which, according to Weller et al. (2005), is not necessarily conducive for engaging learners in an interactive VLE experience. A radical approach would suggest that the institution should consider whether to continue to use WOLF as an in-house system or adopt a hybrid/component approach as put forward by Weller et al. (2005).

In terms of the discussion group facility, students commented on the need for anonymity, and the increased motivation this would lead to in terms of engaging in the discussions.

If it [the discussion group] was anonymous, it would help as other students wouldn't know who you were.

It would appear that an inherent design fault of WOLF is its inability to make discussion forums anonymous.

\section{Conclusions and recommendations}

The paper reported the findings of focus group interviews, and therefore the generalisability of findings to other institutions, or to other students on the same course, should be viewed with caution due to the relatively small sample size involved. Findings suggest that a number of factors determine interaction with a VLE, including student learning style and motivational approach, and the design and functionality of the VLE. Based on the results of the study, three recommendations should be put forward as a means of enhancing interactive WOLF usage.

First, the content of work needs to be relevant, useful and at the correct level for the student. Of particular relevance is the relationship between the skills needed to complete the activity and the skills needed to deliver a successful grade for the assignment in the module. It needs to be clear that the information gained by using WOLF will help students in improving their grades, with an emphasis on students using WOLF and not downloading materials. In terms of enhancing forum engagement, discussion forums should be made anonymous. To promote engagement, the lecturer also needs to set stricter guidelines, ensuring that discussion groups have a start and end point and that no more points can be added after the discussions are closed. In addition, the lecturer should provide a summary of the key points made and email or distribute the summary of forum discussions to the whole class, providing praise for those who engaged with it.

Second, technical and design issues need to be addressed within WOLF. Any technologybased support needs to be easy to use. It should be noted that an updated version of WOLF has recently been implemented which incorporates many of the suggested features, including embedded collaborative activities within weekly sessions and the ability to provide for anonymous discussion forums.

Third, awareness issues and initial guidance should be developed to introduce students sufficiently to WOLF. The downloading of lecture material merely develops a culture of using the VLE in a particular way. Students need to be initiated into using the full range of VLE capabilities from the outset of their learning journey. The encouragement and monitoring of regular habits in using WOLF, including the activities, should also be undertaken. 
The implementation of a VLE, exploring its full capability and potential, presents many challenges, which this study has highlighted, and there is no easy solution. This study has noted a number of areas for further research. These include further analysis of the learning styles of a range of students using VLEs. Some comparison needs to be made between students on different programmes such as traditional humanities subjects and those studying vocational programmes such as Leisure and Tourism. Further research also needs to be conducted into the confidence levels of students and their use of VLE activities for learning. Finally, as this research was predominately based around groups of students that were relatively small in size, further research needs to explore the differences in the use of VLEs with large groups as opposed to small groups.

\section{Acknowledgement}

This project was supported by a research grant from the Centre of Excellence in Learning and Teaching at the University of Wolverhampton.

\section{References}

Berg, B. L. (2001) Qualitative Research Methods for the Social Sciences. (4th edition). London: Allyn and Bacon.

Boyle, F. (2005) The Implementation of a VLE: not so virtual after all. Serials, 18(3), 179-183.

Chou, S. W. and Liu, C. H. (2005) Learning Effectiveness in a Web-Based Virtual Learning Environment: a learner control perspective. Journal of Computer Assisted Learning, 21, 65-76.

Dale, C. (2003) Carry on Talking: the use of online discussion groups as a learning tool. LINK 8. Oxford: LTSN Hospitality, Leisure, Sport and Tourism. 11-12.

Dale, C. and Lane, A. (2004) Carry on Talking: using online discussion forums as a learning tool. Journal of Hospitality, Leisure, Sport and Tourism Education, 3(1), 53-59.

Dale, C. and McCarthy, P. (2006) I Like Your Style: the learning approaches of leisure, tourism and hospitality students studying generic modules. Journal of Hospitality, Leisure, Sport and Tourism Education, 5(2), 48-58.

Enjelvin, G. (2005) Investigating VAT (Value-Adding Technologies) and e-ffectiveness in a French Department, Journal of Further and Higher Education, 29(2), 155-167.

Gibbs, G. R. (1999) Learning How to Learn Using a Virtual Learning Environment for Philosophy. Journal of Computer Assisted Learning, 15, 221-231.

Hakkinen, P. (2003) Collaborative Learning in Networked Environments: interaction through shared workspaces and communication tools. Journal of Education for Teaching, 29(3), 279-282.

Hall, R. (2001) Observations on a Year of Using the Wolverhampton On-Line Learning Framework (WOLF). Journal of Hospitality, Leisure, Sport, Tourism, 1(2), 65-70.

Haven, C. and Botterill, D. (2003) Virtual Learning Environments in Hospitality, Leisure, Tourism and Sport: a review. Journal of Hospitality, Leisure, Sport and Tourism Education, 2(1), 70-92.

Johnson, C. (2005) Lessons Learned from Teaching Web-Based Courses: the 7-year itch. Nursing Forum, 40 (1), 11-17.

Khutan, R. (2003) An Examination of Communication by Students on the Wolverhampton Online Learning Framework in the Teaching of Sensitive Subjects: does using WOLF prohibit or promote communication and thus learning. Learning and Teaching Projects 2002/03. CELT, University of Wolverhampton.

Lane, A. M. et al. (2006) Differentiating Work for Research Methods Via On-line Learning Resources. Journal of Further and Higher Education, 30, 295-302.

Miles, R. et al. (2006) Critical Questions for WOLF: an evaluation of the use of a VLE in the teaching and assessment of English Studies, Learning and Teaching Projects 2004/05. CELT, University of Wolverhampton.

Pavey, J. and Garland, S. (2004) The Integration and Implementation of a Range of E-tivities to Enhance Students' Interaction and Learning. Innovations in Education and Teaching International, 41(3). 
Dale and Lane (2007) A Wolf in Sheep's Clothing? An Analysis of Student's Engagement with Virtual Learning Environments

Protheroe, R. and Hill, D. (2003) Traditional Learning vs Technology Based Learning (TBL) an evaluation of the effectiveness of the Wolverhampton Online Learning Framework (WOLF). Learning and Teaching Projects 2002/03. CELT, University of Wolverhampton.

Roberts, C. and Simkins, A. (2002) An Evaluation of Deep Learning Achieved by Students Studying Environmental Science Modules Using the Wolverhampton Online Learning Framework. Learning and Teaching Projects 2001/02. CELT, University of Wolverhampton.

Stefanov, K. et al. (1998) Design Issues of a Distance Learning Course on Business on the Internet. Journal of Computer Assisted Learning, 14, 83-90.

Thurston, A. (2005) Building Online Learning Communities. Technology, Pedagogy and Education, 14(3), 353-370.

University of Wolverhampton (2002) Learning and Teaching Strategy 2002-2005. CELT, University of Wolverhampton.

Weller, M. et al. (2005) Students' Experience of Component Versus Integrated Virtual Learning Environments. Journal of Computer Assisted Learning, 21, 253-259.

Whitworth, A. (2005) The Politics of Virtual Learning Environments: environmental change, conflict, and e-learning. British Journal of Educational Technology, 36(4), 685-691.

Wise, A. (2005) Virtual Learning Environments: setting the scene. Serials, 18(2), 107-115. 